\title{
Correspondence
}

TO THE EDITOR, British Journal of Venereal Diseases

\section{Risk of ectopic pregnancy after salpingitis}

Sir,

Our surveillance of the complications of sexually transmitted diseases in Canada uses primarily data on discharges from hospital, which are collected uniformly by Statistics Canada from all hospitals in the ten provinces. This is a reliable source of information on the incidence of ectopic pregnancies, but is deficient in respect of the two other complications of current interest to us, namely infertility and salpingitis. For the latter condition, we can directly measure only the (presumably more severe) acute and chronic cases in patients admitted to hospital.

Using historical data on ectopic pregnancy and applying a priori estimates obtained from published reports, we have been able to estimate the incidence of one risk factor (salpingitis) in a segment of the Canadian population.

In the years 1971-4 there were 9986 admissions to hospital for which ectopic pregnancy was the primary diagnosis; an incidence of 52 per 100000 women aged 15-44. This can be regarded as a complete count of ectopic pregnancies terminating in Canadian hospitals. A more accurate way - of estimating the risk of ectopic pregnancy is as a proportion of all reported pregnancies (live births, stillbirths, legal abortions, and ectopic pregnancies). This gives an incidence of 6.2 per 1000 pregnancies for 1971-4. In 1980 there were 4123 - ectopic pregnancies, an incidence of 9.3 per 1000 pregnancies. What can these figures tell us about salpingitis?

Weström et al found that half the women who had ectopic pregnancies in Lund, Sweden during 1970-4 had evidence of prior salpingitis and that the risk of ectopic pregnancy after salpingitis was seven times agreater than in women who had never had salpingitis.' If we apply these estimates to - our figures for ectopic pregnancies during 1971-4, we can show that: the underlying risk of ectopic pregnancy in the absence of salpingitis was 3.5 per 1000 pregnancies; one in eight $(12.5 \%)$ women becoming pregnant had had salpingitis; and the population attributable risk proportion ${ }^{2}$ of ectopic pregnancy due to salpingitis was 0.43 . That is, $43 \%$ of ectopic pregnancies can be attributed to previous salpingitis.

Ory et $a l^{3}$ and Rubin et $a l^{4}$ suggested that the increasing incidence of ectopic pregnancies in the United States in the 1970s resulted from an increasing incidence of salpingitis. Assume this to be true of Canada. That is, assume that the increased incidence of ectopic pregiıancies was caused by the epidemic of sexually transmitted diseases and its consequent pelvic inflammatory disease. On the further assumption that other factors causing ectopic pregnancy have remained the same, we can use the simple attributable risk model to derive the following for 1980: $3127(76 \%)$ of the 4123 cases of ectopic pregnancy occurred in women with fallopian tubes damaged by salpingitis; $31 \%$ of women becoming pregnant in 1980 had had salpingitis; and the population attributable risk proportion of ectopic pregnancy due to salpingitis was $0 \cdot 65$.

The most interesting result of this modelling is that if salpingitis (sexually transmitted or not) were responsible for the increasing incidence of ectopic pregnancy in Canada, the incidence of damage to fallopian tubes induced by salpingitis in Canadian women at risk of pregnancy must have risen from $12 \cdot 5 \%$ to $31 \%$ in the decade 1971-80. Because estimations of risk in Lund cannot be generalised to Canada, however, further data must be examined to test the hypothesis that salpingitis was a factor in the increased incidence of ectopic pregnancy. A retrospective study to estimate the incidence of salpingitis in a Canadian population is planned to test this hypothesis.

\section{Yours faithfully,} J C Hockin

Bureau of Epidemiology,

Laboratory Centre for Disease Control, Ottawa, Canada K1A 0L2

\section{References}

1. Westrőm L. Bengtsson LPh, Mårdh P-A. Incidence, trends, and risks of ectopic pregnancy in a population of women. Br Med J 1981;282: 15-8.
2. MacMahon B, Pugh TF Epidemiology: principles and methods. Boston: Little, Brown, 1970.

3. Ory HW, and the Women's Health Study. Ectopic pregnancy and intrauterine contraceptive devices: new perspectives. Obstet Gynecol 1981;52: 137-44.

4. Rubin GL, Peterson HB, Dorfman SF, et al Ectopic pregnancy in the United States 1970 through 1978. JAMA 1983;249:1725-9.

TO THE EDITOR, British Journal of Venereal Diseases

\section{Condylomata acuminata in children}

Sir,

We read with great interest the article of Baruah et al on perianal condylomata acuminata in a male child (Br J Vener Dis $\overrightarrow{0}$ $1984 ; 60: 60-1)$. The authors stated that + "This is probably the first report of histologically confirmed perianal condylomata acuminata occurring in a child." They also stated that: "Vulval warts have been described in girls aged between 18 months and puberty."

Unfortunately, the authors overlooked our case report of perianal condylomata acuminata in a 13 month old girl. ${ }^{1}$ In this case we confirmed the diagnosis histologically. Thus Baruah et al were not the first to confirm histologically condylomata $\stackrel{\mathscr{\rho}}{\square}$ acuminata in a child. Our case was also out- $\bar{\sigma}$ standing because the patient was a very young girl with perianal, and not vulval, condylomata acuminata.

Yours faithfully, A Ingber

M H Grunwald D E J Feuerman 을

Department of Dermatology,

Beilinson Medical Center,

Tel Aviv University,

Sackler School of Medicine, Israel

Reference

1. Ingber A, Grunwald MH, Feuerman EJ. ণ্ Perianal condylomata acuminata bei einem 13 Monate alten Mădchen. Z Hautkr 1982;58: 1200-2. 